Research Article

\title{
Genetic diversity of carotenoid-rich bananas evaluated by Diversity Arrays Technology (DArT)
}

\author{
Edson P. Amorim ${ }^{1}$, Alberto D. Vilarinhos ${ }^{1}$, Kelly O. Cohen ${ }^{2}$, Vanusia B.O. Amorim ${ }^{1}$, \\ Janay A. dos Santos-Serejo ${ }^{1}$, Sebastião Oliveira e Silva ${ }^{1}$, Kátia N. Pestana ${ }^{1}$, Vânia J. dos Santos ${ }^{1}$, \\ Norma S. Paes ${ }^{2}$, Damares C. Monte ${ }^{2}$ and Ronaldo V. dos Reis ${ }^{1}$ \\ ${ }^{1}$ Embrapa Mandioca e Fruticultura Tropical, Cruz das Almas, BA, Brazil. \\ ${ }^{2}$ Embrapa Recursos Genéticos e Biotecnologia, Brasília, DF, Brazil.
}

\begin{abstract}
The aim of this work was to evaluate the carotenoid content and genetic variability of banana accessions from the Musa germplasm collection held at Embrapa Cassava and Tropical Fruits, Brazil. Forty-two samples were analyzed, including 21 diploids, 19 triploids and two tetraploids. The carotenoid content was analyzed spectrophotometrically and genetic variability was estimated using 653 DArT markers. The average carotenoid content was $4.73 \mu \mathrm{g} \cdot \mathrm{g}^{-1}$, and ranged from $1.06 \mu \mathrm{g} . \mathrm{g}^{-1}$ for the triploid Nanica (Cavendish group) to $19.24 \mu \mathrm{g} . \mathrm{g}^{-1}$ for the triploid Saney. The diploids Modok Gier and NBA-14 and the triploid Saney had a carotenoid content that was, respectively, 7-fold, 6-fold and 9 -fold greater than that of cultivars from the Cavendish group $\left(2.19 \mu \mathrm{g} . \mathrm{g}^{-1}\right)$. The mean similarity among the 42 accessions was 0.63 (range: 0.24 to 1.00 ). DArT analysis revealed extensive genetic variability in accessions from the Embrapa Musa germplasm bank.
\end{abstract}

Key words: diploids, germplasm, molecular markers, Musa sp., variability.

Received: March 25, 2008; Accepted: July 21, 2008.

\section{Introduction}

Fruit consumption has increased markedly in recent years, mainly because of its nutritional value and therapeutic effects. Fruits contain distinct phytochemicals, many of which have antioxidant properties that delay aging and prevent diseases, including certain types of cancer. Compounds such as $\beta$-carotenes and vitamins $C$ and $E$ are important antioxidant components of fruits (Wang et al., 1997).

Bananas are widely consumed, primarily because of their low cost and their potential as functional and nutraceutical food. Brazil is the second largest banana producer in the world, with a production of 7.1 million tons in 2006 from $\sim 500,000$ hectares of plantations (FAO, 2008). Currently, commercial cultivars, especially those of the Cavendish group, do not contain significant amounts of substances with nutritional or therapeutic potential, such as polyphenols, vitamin $\mathrm{C}$ and carotenoids. In contrast, some banana genotypes identified in germplasm banks have high contents of these substances (Setiawan et al., 2001; Someya et al., 2002; Englberger et al. 2003a,b,c, 2005; Melo et al., 2006; Wall, 2006; Davey et al., 2007). Embrapa Cas-

Send correspondence to Edson P. Amorim. Embrapa Cassava and Tropical Fruits, 44380-000 Cruz das Almas, BA, Brazil. E-mail: edson@cnpmf.embrapa.br. sava and Tropical Fruits has an active banana germplasm bank created through the introduction of local germplasm and from international collections. This germplasm bank consists of more than 400 accessions maintained in the field, including wild diploids, triploids and tetraploids.

Determination of the carotenoid content and genetic variability of these genotypes using DNA molecular markers can provide information that is useful in parental selection for crosses between divergent genotypes and for developing novel cultivars with functional properties. Several molecular markers, especially those associated with polymerase chain reaction (PCR)-based methods, including restriction fragment length polymorphism (AFLP), random amplified polymorphic DNA (RAPD) and microsatellites or simple sequence repeats (SSR), have been widely used to estimate genetic variability, choose genitors and investigate phylogenetic relationships among bananas (Creste et al., 2003, 2004; Wan et al., 2005; Ning et al., 2007; Wang et al., 2007; Jain et al., 2007; Ruangsuttapha et al., 2007).

Diversity arrays technology (DArT) is a novel genotyping technique that was originally developed for rice (Jaccoud et al., 2001) but has been applied to cassava, wheat and Arabidopsis thaliana (Wittenberg et al., 2005; Xia et al., 2005; Stodart et al., 2007; White et al., 2008). DArT is an inexpensive technique that is based on hybridization and amplification, requires only a small amount of 
DNA and provided ample genome coverage (Stodart et al., 2007).

The aims of this work were to quantify the total carotenoid content of 42 accessions of the banana germplasm bank held at Embrapa Cassava and Tropical Fruits, including diploids (AA), triploids (AAA, AAB and $\mathrm{ABB}$ ) and tetraploids (AAAB), and to estimate the genetic variability by using DArT molecular markers to aid the choice of genitors for crosses done in the banana breeding program at Embrapa. To our knowledge, this is the first report on the use of DArT to evaluate banana diversity.

\section{Material and Methods}

\section{Plant material}

Forty-two banana accessions were used, including diploids (AA), triploids (AAA, $\mathrm{AAB}$ and $\mathrm{ABB}$ ) and tetraploids (AAAB) maintained in the active banana germplasm bank at Embrapa Cassava and Tropical Fruits (Cruz das Almas, BA, Brazil). The accessions investigated were originally included in the germplasm bank based on their level of functional compounds such as total carotenoid content. The presence of nutraceutical compounds was recently introduced as an additional criterion for banana selection in breeding programs at Embrapa. Table 1 shows the level of ploidy, origin, color pulp, and carotenoid content of the accessions used in this work.

\section{Carotenoid analysis}

The carotenoid content was determined spectrophotometrically, as described by Rodriguez-Amaya (1999). Banana samples $(10 \mathrm{~g})$ were macerated in a mortar containing celite and cold acetone and filtered through a sintered glass funnel. The extract was transferred to a separation funnel containing petroleum ether and ethylic ether (1:1, $\mathrm{v} / \mathrm{v}$ ) and the acetone:petroleum ether:ethylic ether mixture was washed repeatedly with distilled water the acetone was completely removed. The extract was dried with sodium sulfate, transferred to a suitable volumetric flask, and the volume was adjusted with petroleum ether. The carotenoid content was determined spectrophotometrically at $450 \mathrm{~nm}$ in a $1-\mathrm{cm}$ cuvette. The samples were assayed in duplicate.

\section{Diversity analysis}

\section{DNA extraction}

Genomic DNA was extracted from leaves of the different genotypes by the cetyltrimethylammonium bromide (CTAB) method proposed by Doyle and Doyle (1990). After DNA extraction, the samples were stored in microtiter plates and shipped to Diversity Arrays Technology (DArT P/L, PO Box 7141, Yarralumba, ACT 2600, Australia), where the DArT analyses were done. The preparation of the Pst//TaqI genomic representation DNA samples for DArT

Table 1 - Carotenoid content of 42 accessions from the banana (Musa) germplasm collection at Embrapa Cassava and Tropical Fruits.

\begin{tabular}{|c|c|c|c|c|c|c|c|c|c|}
\hline Accession / ITC & Ploidy & Origin & Pulp color & $\mathrm{CC}$ & Accession & Ploidy & Origin & Pulp color & $\mathrm{CC}$ \\
\hline Modok Gier & AA & New Guinea & Orange & $16.05 \pm 0.41^{*}$ & Ambei & AAA & New Guinea & Orangish-yellow & $4.22 \pm 0.29$ \\
\hline NBA 14 / 0267 & AA & New Guinea & Orange & $13.04 \pm 0.05$ & Bakar / 1064 & AAA & Indonesia & Yellow & $3.98 \pm 0.62$ \\
\hline Khai / 0532 & AA & Thailand & Orangish-yellow & $9.02 \pm 0.22$ & Figue Rose Naine / 1159 & AAA & France & Yellow & $3.50 \pm 0.32$ \\
\hline Jaran / 0678 & AA & Indonesia & Orangish-yellow & $8.23 \pm 0.79$ & Highgate / 0263 & AAA & Honduras & Yellow & $3.34 \pm 0.51$ \\
\hline SN2 & AA & New Guinea & Yellow & $7.23 \pm 0.71$ & Lacatan / 0768 & AAA & France & Yellow & $3.18 \pm 0.16$ \\
\hline Malbut & AA & New Guinea & Yellow & $6.87 \pm 0.24$ & Canela & AAA & Brazil & Yellow & $2.86 \pm 0.44$ \\
\hline Ouro & AA & Brazil & Yellow & $5.91 \pm 0.38$ & Gros Michel / 0484 & AAA & Brazil & Cream & $2.81 \pm 0.67$ \\
\hline PA Phatthalung & AA & Thailand & Yellow & $3.59 \pm 0.34$ & $\mathrm{Nam} / 1303$ & AAA & Thailand & Yellow & $2.77 \pm 0.14$ \\
\hline 2803-01 & AA & Brazil & Yellow & $3.53 \pm 0.14$ & Pagatow & AAA & New Guinea & Yellow & $2.64 \pm 0.25$ \\
\hline M-48 & AA & Equador & Yellow & $3.51 \pm 0.19$ & Valery / 0048 & AAA & Indonesia & Yellow & $2.32 \pm 0.24$ \\
\hline M-61 & AA & Equador & Yellow & $3.37 \pm 0.52$ & Nanica & AAA & Brazil & White & $1.06 \pm 0.04$ \\
\hline Khi Maeo & AA & Thailand & Yellow & $3.32 \pm 0.15$ & P. Nangka / 0004 & $\mathrm{AAB}$ & Thailand & Yellow & $4.59 \pm 0.01$ \\
\hline Tongat / 0063 & AA & Honduras & Yellow & $3.01 \pm 0.31$ & Saney & $\mathrm{AAB}$ & New Guinea & Orange & $19.24 \pm 3.22$ \\
\hline Pipit / 0685 & AA & Indonesia & Beige & $2.95 \pm 0.14$ & AAB no name & $\mathrm{AAB}$ & Honduras & Orange & $8.40 \pm 0.34$ \\
\hline F3P4 & AA & Equador & Yellow & $2.52 \pm 0.03$ & Terra & $\mathrm{AAB}$ & Brazil & Orangish-yellow & $5.83 \pm 1.16$ \\
\hline Lidi / 0395 & AA & Honduras & Beige & $2.45 \pm 0.08$ & Thap Maeo / 1301 & $\mathrm{AAB}$ & Honduras & Cream & $3.77 \pm 0.04$ \\
\hline Sowmuk / 0266 & AA & New Guinea & Yellow & $2.23 \pm 0.07$ & Figo Cinza & $\mathrm{ABB}$ & Brazil & Yellow & $2.15 \pm 0.01$ \\
\hline Jambi & AA & Indonesia & Beige & $1.47 \pm 0.01$ & Ouro da Mata / 0261 & $\mathrm{AAAB}$ & Brazil & Orangish-yellow & $4.70 \pm 0.02$ \\
\hline Tuugia & AA & Hawaii & White & $1.41 \pm 0.04$ & Porp & $\mathrm{AAAB}$ & New Guinea & Beige & $2.34 \pm 0.06$ \\
\hline
\end{tabular}

ITC: International Transit Centre. CC: carotenoid content $\left(\mu \mathrm{g} \cdot \mathrm{g}^{-1}\right)$. *: means ( \pm standard error) of two replicates per accession. 
and the methodology for DArT, as provided by DArT P/L, are described below.

\section{DArT procedure}

Restriction enzyme digestion and adapter ligation

A combined digestion/ligation reaction was prepared by adding $1 \mu \mathrm{L}$ of DNA sample to $9 \mu \mathrm{L}$ of digestion/ligation mix. The digestion/ligation reaction mixture contained $1 \mu \mathrm{L}$ of $10 \mathrm{X}$ RE buffer (100 mM Tris-acetate (OAc), $500 \mathrm{mM}$ KOAc, $100 \mathrm{mM} \mathrm{Mg}(\mathrm{OAc})_{2}, 50 \mathrm{mM}$ DTT, pH 7.8), $0.1 \mu \mathrm{L}$ of BSA (New England Biolabs), $0.2 \mu \mathrm{L}$ of $50 \mathrm{mM}$ ATP, $0.1 \mu \mathrm{L}$ of $5 \mu \mathrm{M}$ Pst I adapter, $0.1 \mu \mathrm{L}$ of Pst $(20 \mathrm{U} / \mu \mathrm{L}$ NEB), $0.1 \mu \mathrm{L}$ TaqI (20 U/ $\mu \mathrm{L}$ NEB), $0.2 \mu \mathrm{L}$ of T4 DNA ligase (30 Weiss units/ $\mu \mathrm{L} \mathrm{NEB}$ ) and $7.2 \mu \mathrm{L}$ of ultrapure water. The samples were incubated at $37^{\circ} \mathrm{C}$ for $90 \mathrm{~min}$ and at $60{ }^{\circ} \mathrm{C}$ for $90 \mathrm{~min}$, heat inactivated at $80{ }^{\circ} \mathrm{C}$ for $20 \mathrm{~min}$ and stored at $-20{ }^{\circ} \mathrm{C}$ until used.

\section{PCR amplification of the genomic representation (target preparation)}

PCR was used to create a genomic representation containing Pst I fragments that (i) showed no restriction sites for the frequent cutter used for redigestion and (ii) were short enough to be efficiently amplified. The number of PCR cycles was kept to a minimum to limit the bias towards fragments that were amplified more efficiently than others. The starting parameters for optimization are described below for the Pst $\mathrm{I} / \mathrm{Taq}$ I method.

Forty-nine microliters of PCR mix were added to $1 \mu \mathrm{L}$ of Pst $\mathrm{I} /$ TaqI digestion/ligation reaction used as the PCR template. The PCR mix consisted of (volumes per reaction): $5 \mu \mathrm{L}$ of 10x PCR buffer (100 mM Tris-HCl pH 8.3, $500 \mathrm{mM} \mathrm{KCl}, 15 \mathrm{mM} \mathrm{MgCl} 2,0.1 \%$ gelatin; Sigma), $1 \mu \mathrm{L}$ of $10 \mathrm{mM}$ dNTPs (Sigma), $2 \mu \mathrm{L}$ of $10 \mu \mathrm{M}$ Pst $\mathrm{I}+0,2 \mu \mathrm{L}$ of REDTaq (1 U/ $\mu \mathrm{L}$; Sigma) and $39 \mu \mathrm{L}$ of ultrapure water. The PCR amplification program consisted of an initial step at $94^{\circ} \mathrm{C}$ for $1 \mathrm{~min}, 30$ cycles at $94^{\circ} \mathrm{C}$ for $20 \mathrm{~s}, 58^{\circ} \mathrm{C}$ for $40 \mathrm{~s}$, and $72{ }^{\circ} \mathrm{C}$ for $1 \mathrm{~min}$, and a final step at $72{ }^{\circ} \mathrm{C}$ for $7 \mathrm{~min}$. Five microliters of PCR product were analyzed on $1.2 \%$ agarose gels to confirm that a homogeneous smear of fragments was obtained and to visualise the size distribution.

For hybridization and scanning, the targets were labelled with fluorescent dye (Cy3) and hybridized with the reference (Topo) labeled with FAM (Carboxyfluorescein) and hybridized to the array containing 6,000 DArT clones. Clone information cannot be made available because of data protection recommendations. After overnight hybridization at $62{ }^{\circ} \mathrm{C}$, the arrays were washed and scanned at $20 \mu \mathrm{m}$ resolution at $543 \mathrm{~nm}(\mathrm{Cy} 3)$ and $488 \mathrm{~nm}$ (FAM) on na LS300 confocal laser scanner (Tecan, Grödig, Austria).

\section{DArT data analysis}

Array images were analyzed using DArTsoft 7.4 (Diversity Arrays Technology P/L, Canberra, Australia). The software automatically recognizes the array features using a seeded-region-growth algorithm and, for each fluorescent channel, reports the average and standard deviation (SD) of pixel intensities within and around each array feature, the fraction of saturated pixels, and the number of pixels within each feature, among other parameters. The logarithm of the ratio between the background-subtracted averages of feature pixels in the $\mathrm{Cy} 3$ and $\mathrm{Cy} 5$ channel (= $\log [$ Cy3target/Cy5reference]) was used as a measure of the difference in the abundance of the corresponding DNA fragment for the representations hybridized to an array. The values of $\log [\mathrm{Cy} 3 / \mathrm{FAM}]$ and $\log [\mathrm{Cy} 5 / \mathrm{FAM}]$, approximate measures of the amount of hybridization signal per amount of DNA spotted on the array, were used for quality control purposes.

Six hundred and fifty-three high-quality markers were scored. The results of the DArT analysis were expressed as a matrix (0-1). The mean genetic similarity among the genotypes was estimated by using a simple matching coefficient (Sokal and Michener, 1958). Cluster analysis was done by using the unweighted pair-group method with arithmetic average (UPGMA) as implemented in NTSYS-pc v. 2.1 (Rohlf, 2000). Principal component analysis (PCA)-based clustering with the sub-routine EIGEN was used to assess and visualize the level of ploidy (diploids, triploids and tetraploids) in diversity space (as opposed to visualizing only the genetic similarity among the accessions).

The cophenetic correlation coefficient was calculated and the Mantel test (Mantel, 1967) was used to check the fitness of a cluster analysis to the matrix on which it was based. Bootstrap analysis was used to verify the number of DArT markers needed to precisely determine the estimates of genetic similarity among the 42 banana accessions. This analysis was done with the statistical software GQMol (Cruz and Schuster, 2004) which estimates the correlation between values from the original distance matrix with those of other matrices obtained by re-sampling from different sample sizes (Amorim et al., 2006). The software also calculates a value of stress (S) that indicates an adjustment between the original matrix and considers the 653 markers and re-sampling matrices (Kruskal, 1964).

\section{Results}

Genotypes with a pulp color ranging from yellow to orange had a higher content of total carotenoids compared to those with white or beige pulp (Table 1 and Figures 1 and 2). Pulp color was found to be a suitable phenotypic criterion for making inferences about variability in the total carotenoid content of segregating populations. The mean content of total carotenoids among the 42 accessions was $4.73 \mu \mathrm{g} . \mathrm{g}^{-1}$, and ranged from $1.06 \mu \mathrm{g} \cdot \mathrm{g}^{-1}$ for the triploid Nanica (Cavendish group) to $19.24 \mu \mathrm{g} . \mathrm{g}^{-1}$ for the triploid Saney (Table 1). 


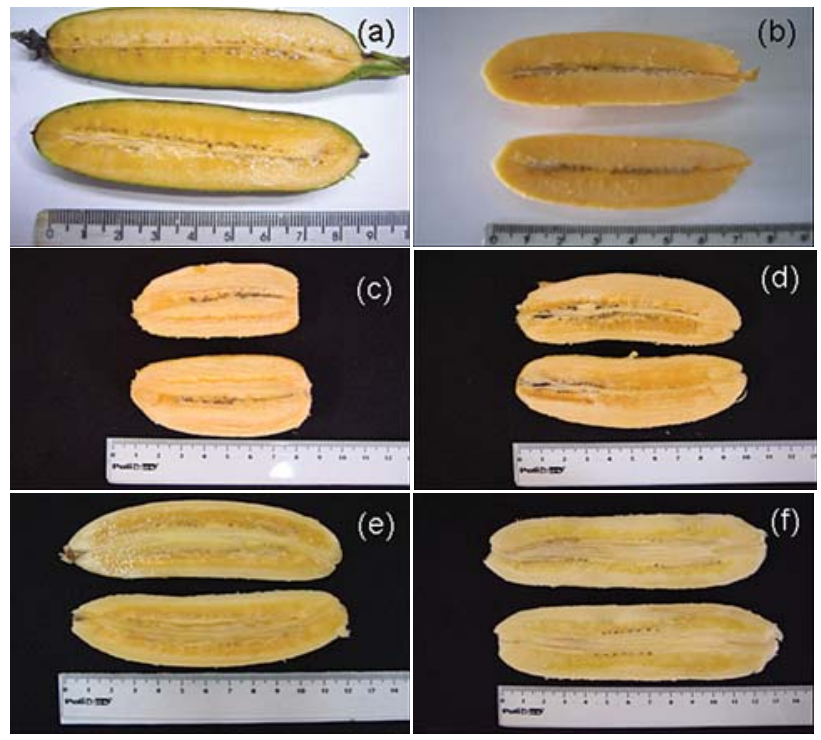

Figure 1 - Banana accessions with a high carotenoid content and pulp color ranging from yellow to orange. Diploids: Modok Gier (a) and NBA-14 (b), triploids: Saney (c) and AAB no name (d), tetraploids: Ouro da Mata (e) and Porp (f)
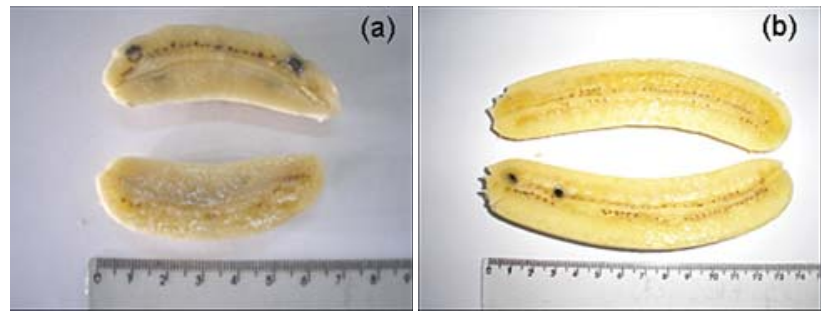

Figure 2 - Banana accessions with a low carotenoid content and beige or white pulp color. (a) diploid Jambi and (b) triploid Markatooa. Detail: presence of seeds.

Within the diploid group, the mean carotenoid content was $5.24 \mu \mathrm{g} . \mathrm{g}^{-1}$, with high levels for the diploids Modok Gier (16.05 $\left.\mu \mathrm{g} \cdot \mathrm{g}^{-1}\right)$, NBA-14 (13.04 $\left.\mu \mathrm{g} \cdot \mathrm{g}^{-1}\right)$ and Khai $\left(9.02 \mu \mathrm{g} \cdot \mathrm{g}^{-1}\right)$. The mean content among triploids from the genomic groups AAA, AAB and ABB was 2.93, 8.37 and $2.15 \mu \mathrm{g} . \mathrm{g}^{-1}$, respectively. The mean carotenoid content for tetraploids was $3.52 \mu \mathrm{g} . \mathrm{g}^{-1}$ (Table 1). Triploids with the genomic composition $\mathrm{AAB}$ had higher contents of total carotenoids compared to AAA triploids. In the Cavendish group of cultivars, the total carotenoid content was 1.06, 3.18 and $2.32 \mu \mathrm{g} . \mathrm{g}^{-1}$ for the Nanica, Lacatan and Valery genotypes, respectively, with a mean content of $2.19 \mu \mathrm{g} . \mathrm{g}^{-1}$. The carotenoid content of the diploids Modok Gier and NBA-14 and the triploid Saney was, respectively, 7-fold, 6-fold and 9-fold greater than the mean value for the Cavendish group $\left(2.19 \mu \mathrm{g} \cdot \mathrm{g}^{-1}\right)$.

Figure 3 shows that there was extensive genetic variability in the carotenoid contents of the banana accessions, particularly among diploids. The three genotypes with the highest total carotenoid content (Modok Gier, NBA-14,

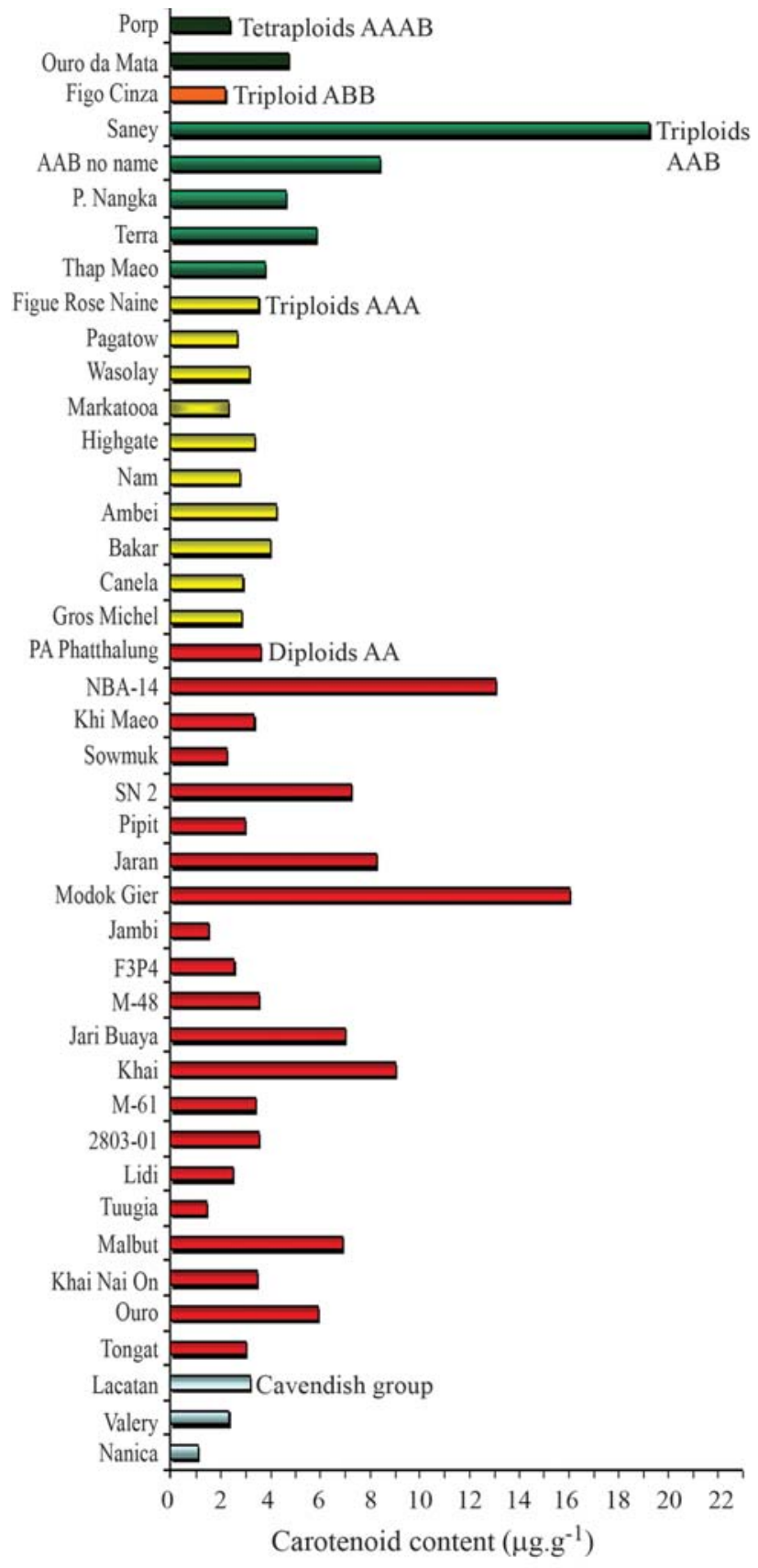

Figure 3 - Carotenoid contents of 42 banana (Musa) accessions in the germplasm collection held at Embrapa Cassava and Tropical Fruits.

and Saney) had the same geographic origin (New Guinea), indicating the possibility of gene flow among them. Our results indicate that it is possible to obtain segregating diploid populations for the trait 'carotenoid content' that could be used to build genetic maps and identify quantitative trait loci (QTL) associated with the trait. In addition, by selecting suitable diploid and triploid genitors it is possible to develop tetraploid cultivars with high carotenoid contents.

Re-sampling analyses showed that 282 DArT markers ( $43 \%$ of the total) were sufficient to obtain a precise estimate of the genetic divergence among the 42 banana 
accessions. The correlation between the matrix considering all 653 markers and the matrix with 282 markers was 0.96 , with a square sum of the deviations $\left(\mathrm{SQ}_{\mathrm{d}}\right)$ of 0.51 and a stress value (E) of 0.052 (Figure 4). These findings indicate that the number of DArT markers analyzed was sufficient to precisely estimate the genetic divergence among the 42 banana accessions. Moreover, $\sim 60 \%$ of the DArT markers were inferred to have similar molecular information, probably as a result of genetic linkage among them in the banana genome. The mean genetic similarity among the 42 accessions was 0.63 , and ranged from 0.24 between the diploid NBA-14 and the triploid Canela to 1.00 between the diploid 2803-01 and the accessions Canela (AAB) and Modok Gier (AA).

Figure 5 shows the dendrogram of genetic similarity obtained by UPGMA based on DArT among the 42 banana accessions investigated. The cophenetic value was high ( $\mathrm{r}=0.92, \mathrm{p}<0.0001,10,000$ permutations $)$ and adequate since values of $r \geq 0.56$ are considered ideal and reflect agreement with the values of genetic similarity (Vaz Patto et al., 2004).

The cut-off value for the dendrogram was assumed to be the mean genetic similarity among all accessions genotyped by DArT (0.63). Based on this value, two major clusters were formed (Figure 5). The carotenoid contents showed no tendency to cluster since accessions with higher carotenoid levels occurred equally in both clusters and, in some cases, with low genetic similarity, e.g., the diploids 2803-01 and NBA-14 (0.24). Similarly, DArT markers did not cluster the accessions based on their genomic group, i.e., diploids (AA), triploids ( $\mathrm{AAA}, \mathrm{AAB}$ and $\mathrm{ABB}$ ) and tetraploids (AAAB). A number of the accessions clustered based on geographic origin, whereas others showed no such correlation (Figure 5 and Table 1).

Figure 6 shows a dendrogram of the 21 diploid genotypes investigated by DArT markers. The average genetic

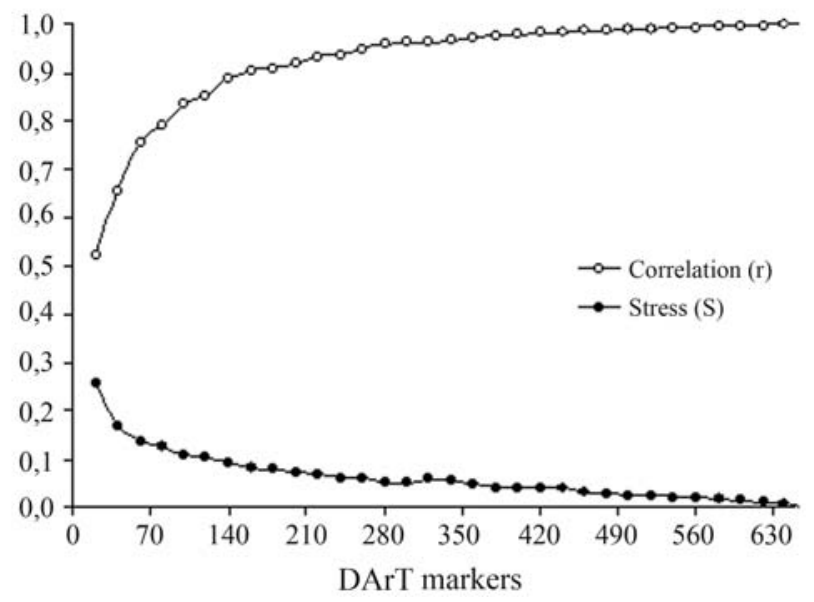

Figure 4 - Bootstrap analysis used to obtain a precise estimate of the genetic similarity among 42 banana (Musa) accessions in the germplasm collection held at Embrapa Cassava and Tropical Fruits. similarity among the diploid accessions was 0.67 , and ranged from 0.24 between NBA- 14 and $2803-01$ to 0.98 between Modok Gier and 2803-01. The accessions were clustered into three groups (Figure 5), although there was no clear separation between accessions with high and low carotenoid contents. The cophenetic value was high $(\mathrm{r}=0.93, \mathrm{p}<0.0001,10,000$ permutations $)$. As with the carotenoid content (Figure 3), DArT analysis also detected significant genetic variability among the 42 banana accessions maintained in the Embrapa germplasm bank (Figures 5 and 6).

Principal component analysis (PCA) reinforced the results obtained with clustering analysis by UPGMA (Fig-

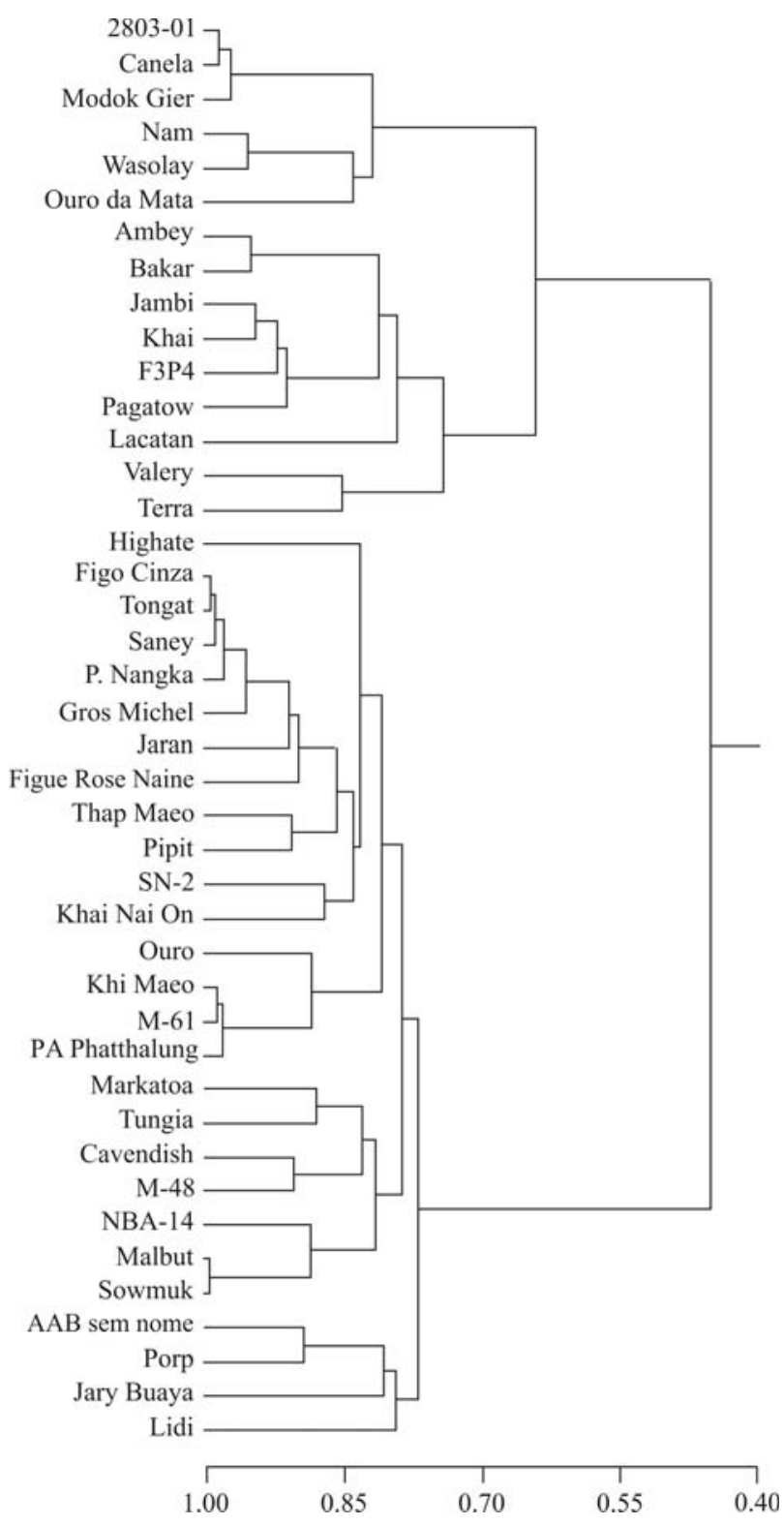

Figure 5 - UPGMA dendrogram for 42 banana (Musa) accessions in the germplasm collection held at Embrapa Cassava and Tropical Fruits. The dendrogram was constructed with NTSYS version 2.0 software (Rohlf 2000) using the simple matching coefficient. 


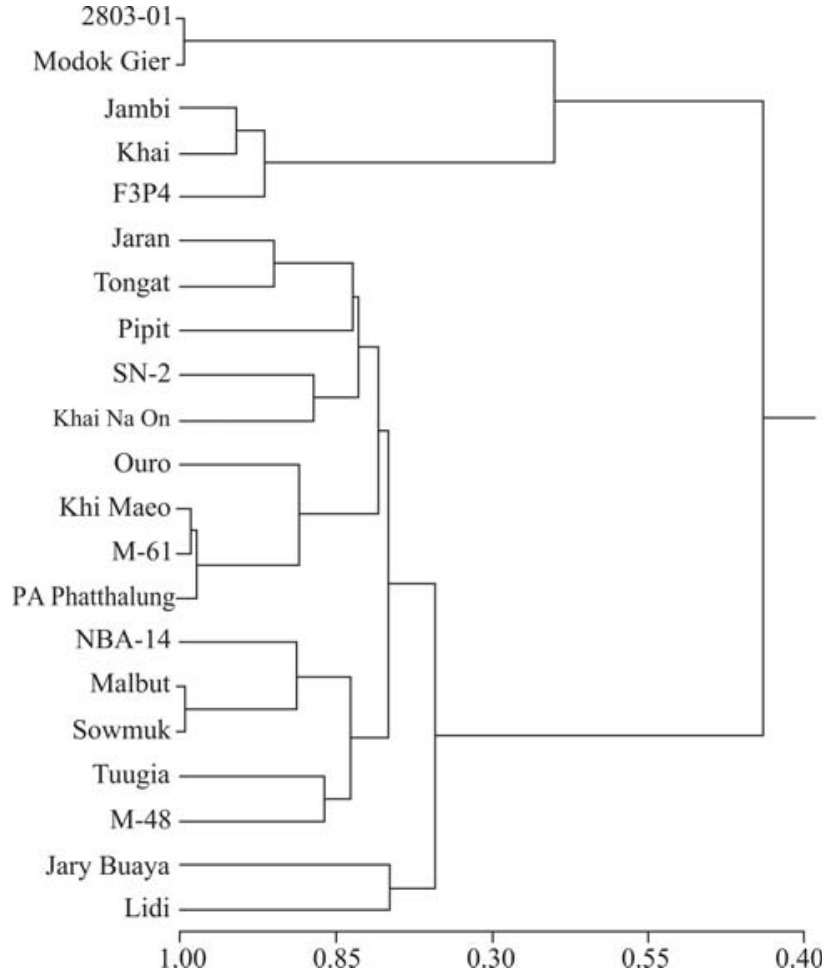

Figure 6 - UPGMA dendrogram for the 21 diploid banana (Musa) accessions in the germplasm collection held at Embrapa Cassava and Tropical Fruits. The dendrogram was constructed as described in Figure 5.

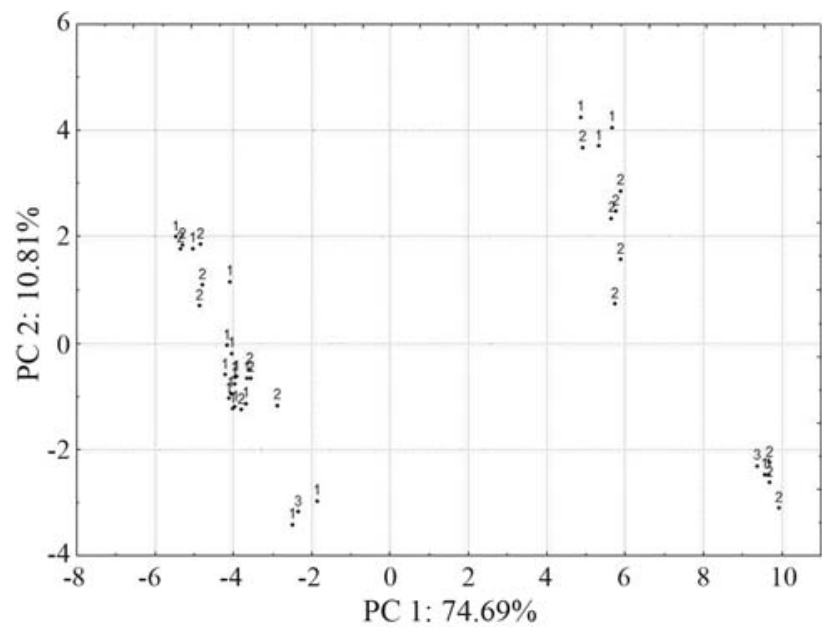

Figure 7 - Clustering obtained by PCA based on pooled DArT data of 42 banana (Musa) accessions in the germplasm collection held at Embrapa Cassava and Tropical Fruits. 1 - diploids, 2 - triploids and 3 - tetraploids.

ure 7). The first and the second components were responsible for $74.7 \%$ and $10.8 \%$ of the genetic variation, respectively. These two components were responsible for $85.5 \%$ of the variation observed among the levels of ploidy (diploids, triploids and tetraploids).

\section{Discussion}

In this work, 42 banana accessions were initially screened based on pulp color, which ranged from yellow to orange. Some genotypes with white and beige pulp were also analyzed to confirm the association between pulp color and carotenoid content. Banana pulp color is directly related to carotenoid content and can be classified into five categories: white, beige, yellow, orangish-yellow and orange (Englberger et al., 2003a,c). Hence, an orangishyellow or orange pulp may be used as a criterion to select suitable genotypes to develop cultivars with a higher carotenoid content.

The mean carotenoid contents obtained here agreed with the results reported by others. Setiawan et al. (2001) reported that the mean $\beta$-carotene content of three samples of Musa paradisiaca was $1.00 \mu \mathrm{g} \cdot \mathrm{g}^{-1}$ (range: 0.72 to $1.22 \mu \mathrm{g} \cdot \mathrm{g}^{-1}$ ). Englberger et al. (2003b) quantified the total carotenoid content in 21 banana accessions, including genotypes from the sections Australimusa and Eumusa. The mean total carotenoid content was $11.13 \mu \mathrm{g} . \mathrm{g}^{-1}$, with values ranging from 0.60 to $53.7 \mu \mathrm{g} \cdot \mathrm{g}^{-1}$. These authors reported a similar value for another 17 banana accessions $\left(9.21 \mu \mathrm{g} . \mathrm{g}^{-1}\right)$ (Englberger et al., 2003c) and Melo et al. (2006) found a value of $10.62 \mu \mathrm{g} \cdot \mathrm{g}^{-1}$ for the cultivar Comprida (Type Terra, AAB). Davey et al. (2007) reported that genotypes from the genomic group $\mathrm{AAB}$ had higher contents of carotenoids compared to those from the AAA group, possible because of the presence of the B genome. Similar results were reported by Englberger et al. (2003a) and Melo et al. (2006).

As shown here, the carotenoid content of some banana genotypes differed from that of Cavendish cultivars by up to 9-fold. In agreement with this, other studies of banana accessions in germplasm banks have reported carotenoid contents up to 25 -fold higher than found in commercial cultivars from the Cavendish group (Englberger et al., 2003a,b,c; Wall, 2006).

The carotenoid content may be influenced by several factors, including the degree of maturation, type of soil, climatic conditions, storage conditions, geographic location and, especially, genotype (Sharrock and Lutsy, 2000; Setiawan et al., 2001; Souza et al., 2004). In the present work, the most important factor was the genotype and the origin (geographic location) since all of the other factors were constant for the accessions in the Embrapa germplasm bank, i.e., the accessions were analyzed at the same stage of maturation, stored under the same conditions and kept under the same environmental conditions.

Re-sampling analyses indicated that the number of DArT markers used was more than sufficient to precisely genotype the 42 banana accessions. The stress value (E) of 0.052 reinforced this conclusion, since $\mathrm{E}$ values $\leq 0.05$ are considered ideal for precise estimation of the genetic variation in a given population (Kruskal, 1964).

Extensive genetic variability was observed among the 42 accessions genotyped using DArT. Similar results were obtained by Creste et al. $(2003,2004)$ who used micro- 
satellite or SSR markers to evaluate diploid and triploid accessions from the Embrapa germplasm bank. The lack of genetic correlation between accessions of common genetic origin is probably related to recent anthropic action that has influenced genotype dispersion (Jarret et al., 1993).

In the present study, several triploid cultivars shared high similarity values with diploid genotypes, e.g., the triploid Nanica, which showed $91 \%$ similarity with the diploid M-48, 84\% similarity with the diploids Khai Nai On and Tuugia and $80 \%$ similarity with the diploids Sowmuk, Jaran and NBA-14. Since Nanica is an export-type triploid cultivar (Cavendish) and exhibits complete female sterility, the high level of similarity with diploids provides novel breeding possibilities.

Molecular analyses have revealed extensive genetic diversity in Musa acuminata (Lannaud et al., 1992; Carreel et al., 1994, 2002; Ude et al., 2002; Ruangsuttapha et al., 2007). In contrast, analyses using RAPD, SSR and AFLP molecular markers have revealed lower levels of genetic variation among banana accessions (Nsabimana and Staden, 2007; Ning et al., 2007; Wang et al., 2007). In this context, the use of DArT markers to clearly define the relationships among and within wild material and to improve diploid and triploid cultivars in germplasm collections could facilitate the prediction of how hybrids will perform, thereby increasing genetic gains.

Our results provide additional information for banana genetic breeding programs by allowing the selection of carotenoid-rich diploids for crosses with triploids to provide novel tetraploid cultivars with improved functional properties. Nutritional (biofortification) and functional breeding, allied with improved productivity and disease resistance, should result in better nutritional value. Since bananas are the most consumed fruit in the world, the ingestion of nutritionally enhanced cultivars could significantly improve consumers health by reducing the incidence of diseases and indirectly decrease spending on public health, which is currently significantly elevated worldwide.

\section{Acknowledgments}

This work was funded by the Generation Challenge Programme/Genotyping Support Service (GSS). S. Silva was supported by a fellowship from CNPq. The authors thank V. Quecini (Embrapa Grape and Wine) for help in drafting the manuscript.

\section{References}

Amorim EP, Amorim VBO, Santos JB, Souza AP and Souza JC (2006) Genetic distance based on SSR and grain yield of inter and intrapopulational maize single cross hybrids. Maydica 51:507-513.

Carreel F, Fauré S, De-Leon DG, Lagoda PJL, Perrier X, Bakry F, Du-Montcel HT, Lanaud C and Horry JP (1994) Évaluation de la diversité génétique chez les bananiers diploids (Musa sp.) Gen Sel Evol 26:125s-136s.
Carreel F, De-Leon DG, Lagoda PJL, Lanaud C, Jenny C, Horry JP and Du-Montcel HT (2002) Ascertaining maternal and paternal lineage within Musa by chloroplast and mitochondrial DNA RFLP analyses. Genome 45:679-692.

Creste S, Tulmann-Neto A, Silva SO and Figueira A (2003) Genetic characterization of banana cultivars (Musa spp.) from Brazil using microsatellite markers. Euphytica 132:259268.

Creste S, Tulmann-Neto A, Vencovsky R, Silva SO and Figueira A (2004) Genetic diversity of Musa diploid and triploid accessions from the Brazilian banana breeding program estimated by microsatellite markers. Gen Res Crop Evol 51:723-733.

Cruz CD and Schuster I (2004) GQMOL - Aplicativo Computacional para Análise de Dados Moleculares e de Suas Associações com Caracteres Quantitativos. UFV, Viçosa.

Davey MW, Stals E, Ngoh-Newilah G, Tomekpe K, Lutsy C, Markham R, Swennen R and Keulemans J (2007) Sampling strategies and variability in fruit pulp micronutrient contents of West and Central African bananas and plantains (Musa sp.). J Agric Food Chem 55:2633-2644.

Doyle JJ and Doyle JL (1990) Isolation of plant DNA from fresh tissue. Focus 12:13-15.

Englberger L, Aalbersberg W, Ravi P, Bonnin E, Marks GC, Fitzgerald MH and Elymore J (2003a) Further analyses on Micronesian banana, taro, breadfruit and other foods for provitamin A, carotenoids and minerals. J Food Comp Anal 16:219-236.

Englberger L, Darnton-Hill I, Coyne T, Fitzgerald MH and Marks GC (2003b) Carotenoid-rich bananas: A potential food source for alleviating vitamin A deficiency. Food Nutr Bull 24:303-318.

Englberger L, Schierle J, Marks GC and Fitzgerald MH (2003c) Micronesian banana, taro, and other foods: Newly recognized sources of provitamin A and others carotenoids. J Food Comp Anal 16:3-19.

Englberger L, Marks GC, Fitzgerald MH and Lippwe K (2005) Food composition data from Federated States of Micronesia. Micronesica 37:195-213.

Jaccoud D, Peng K, Feinstein D and Kilian A (2001) Diversity arrays: A solid state technology for sequence information independent genotyping. Nucleic Acids Res 29:e25.

Jain PK, Saini ML, Pathak H and Gupta VK (2007) Analysis of genetic variation in different banana (Musa species) variety using random amplified polymorphic DNAs (RAPDs). Afr J Biotech 6:1987-1989.

Jarret RL, Vuylsteke DR, Gawel NJ, Pimentel RB and Dunbar LJ (1993) Detecting genetic diversity in diploids bananas using PCR and primers from a highly repetitive DNA sequence. Euphytica 68:69-76.

Kruskal JB (1964) Multidimensional scaling by optimizing goodness of fit to a no metric hypothesis. Psychometrika 29:1-27.

Lannaud C, Du-Montcel HT, Jolivot MP, Glszmann JC and De Leon DG (1992) Variation of ribosomal gene spacer length among wild and cultivated banana. Heredity 68:147-156.

Mantel N (1967) The detection of disease clustering and a generalized regression approach. Cancer Res 37:209-220.

Melo EA, Lima VLAG and Maciel MIS (2006) Polyphenol, ascorbic acid and total carotenoid contents in common fruits and vegetables. Braz J Food Technol 9:89-94. 
Ning SP, Xu LB, Lu Y, Huang BZ and Ge XJ (2007) Genome composition and genetic diversity of Musa germplasm from China revealed by PCR-RFLP and SSR markers. Sci Horticult 114:281-288.

Nsabimana A and Staden JV (2007) Assessment of genetic diversity of Highland bananas from the National Banana Germplasm Collection at Rubona, Rwanda using RAPD markers. Sci Horticult 113:293-299.

Rodriguez-Amaya DB (1999) A Guide to Carotenoid Analysis in Foods, 1st edition. ILSI Press, City, 64 pp.

Rohlf FJ (2000) NTSys-pc: Numerical Taxonomy and Multivariate Analysis System, v. 2.1. Exceter Software, New York.

Ruangsuttapha S, Eimert K, Schoder MB, Silayoi B, Denduangborinpat J and Kanchanapoom K (2007) Molecular phylogeny of banana cultivares on HAT-RAPD. Gen Res Crop Evol 54:1565-1572.

Setiawan B, Sulaeman A, Giraud DW and Driskell JA (2001) Carotenoid content of selected Indonesian fruits. J Food Comp Anal 14:169-176.

Sharrock S and Lutsy C (2000) Nutritive value of banana. In: INIPAB Annual Report. INIPAB, Montpellier, pp 28-31.

Sokal RR and Michener CD (1958) A statistical method for evaluating systematic relationships. Univ Kansas Sci Bull 38:1409-1438.

Someya S, Yoshiki Y and Okubo K (2002) Antioxidant compounds form bananas (Musa cavendish). Food Chem 79:351-354.

Souza SL, Moreira APB, Santana HM and Alencar ER (2004) Conteúdo de carotenos e provitamina A em frutas comercializadas em Viçosa, Estado de Minas Gerais. Acta Sci Agron 26:453-459.

Stodart BJ, Mackay MC and Raman H (2007) Assessment of molecular diversity in landraces of bread wheat (Triticum aestivum L.) held in an ex situ collection with Diversity Arrays Technology (DArT). Aust J Agric Res 58:1174-1182.

Ude G, Pillay M, Nwakanma DC and Tenkouano GUA (2002) Analysis of genetic and sectional relationships in Musa using AFLP markers. Theor Appl Genet 104:1239-1245.
Vaz Patto MC, Satovic Z, Pêgo S and Fevereiro P (2004) Assessing the genetic diversity of Portuguese maize germplasm using microsatellite markers. Euphytica 137:63-72.

Wall M (2006) Ascorbic acid, vitamin A, and mineral composition of banana (Musa sp.) and papaya (Carica papaya) cultivars grown in Hawaii. J Food Comp Anal 19:434-445.

Wan Y, Watanabe JA, Yi SS, Htaik T, Win K, Yamanaka S, Nakamura I and Watanabe KN (2005) Assessment of genetic diversity among the major Myanmar banana landraces. Breed Sci 55:365-369.

Wang H, Cao G and Prior RL (1997) Oxygen radical absorbing capacity of anthocyanins. J Agric Food Chem 45:304-309.

Wang XL, Chiang TY, Roux N, Hao G and Ge XJ (2007) Genetic diversity of wild banana (Musa balbisiana Colla) in China as revealed by AFLP markers. Genet Res Crop Evol 54:1125-1132.

White J, Law JR, Mackay I, Chalmers KJ, Smith JSC, Kilian A and Powell W (2008) The genetic diversity of UK, US and Australian cultivars of Triticum aestivum measured by DArT markers and considered by genome. Theor Appl Genet 116:439-453.

Wittenberg AH, Van Der Lee T, Cayla C, Kilian A, Visser RG and Schouten HJ (2005) Validation of the high-throughput marker technology DArT using the model plant Arabidopsis thaliana. Mol Gen Genet 274:30-39.

Xia L, Peng K, Yang S, Wenzl P, Vicente MC, Fregene M and Kilian A (2005) DArT for high-throughput genotyping of cassava (Manihot esculenta) and its wild relatives. Theor Appl Genet 110:1092-1098.

\section{Internet Resources}

Food and Agriculture Organization (FAO) of the United Nations, www.faostat.fao.org/site/340/default.aspx. (March 19, 2008).

Associate Editor: Everaldo Gonçalves de Barros

License information: This is an open-access article distributed under the terms of the Creative Commons Attribution License, which permits unrestricted use, distribution, and reproduction in any medium, provided the original work is properly cited. 